\title{
Using Calcium Carbonate Whisker in Engineered Cementitious
}

\author{
Composites \\ Jing-ming Cai ${ }^{1}$, Jin-long Pan* \\ ${ }^{1}$ Southeast University Nanjing, \\ Nanjing, China \\ e-mail: caijingming.2009@163.com \\ *Southeast University Nanjing, \\ Nanjing, China \\ e-mail: jinlongp@gmail.com
}

Key words: Calcium carbonate whisker, Polyvinyl alcohol fiber, Mutil-scale, Mechanical behaviors,

\begin{abstract}
A new kind of multi-scale engineered cementitious composite (MS-ECC), which contains polyvinyl alcohol (PVA) fiber and calcium carbonate $(\mathrm{CaCO} 3)$ whisker, was designed from the perspective of multi-scale structure and fracture process of cementitious material. 12 series of MS-ECC proportions was casted and the mechanical properties including compressive strength, uniaxial tension behavior, flexural behavior and microstructures of the mixtures were studied. The results indicates that the strength and ductility of MS-ECC was enhanced with proper addition of $\mathrm{CaCO} 3$ whisker. Moreover, it seems that the PVA fiber can be appropriately reduced due to the existence of $\mathrm{CaCO} 3$ whisker, which is beneficial in decreasing the production cost of fiberreinforced cementitious composites for large-scale construction projects.
\end{abstract}

\section{INTRODUCTION}

Cementitious material, such as concrete and cement mortar, are the most commonly-used construction material, and has proven its versatility in many construction application all over the world. Cementitious material was primarily designed for carrying compression load, however, it was also subjected to tensile stress in real field conditions, such as shrinkage and thermal deformations if the deformation is restrained. Moreover, concrete is a brittle material with low resistance to cracking and the poor durability for concrete structures can be associated with the brittle nature of concrete.

In order to modify the brittle nature of ordinary cementitious material, different fibers including macro- and micro- fibers are used as reinforcements. The macro-fibers, such as polyvinyl alcohol (PVA) fibers [1], steel fibers [2], polypropylene (PP) fibers [3], polyacrylonitrile (PAN) fiber [4], plant fiber [5] and the hybrid fiber of the above [6-9] are widely used in the cementitious material. Among these macro fiber reinforced cementitious composites, engineered cementitious composites (ECC) with ultra-high tensile ductility (above 2\%) and limited crack widths 
(below $100 \mu \mathrm{m}$ ) have emerged as a promising alternative to normal concrete and fiber reinforced concrete for improving structural performance. According to the experimental and theoretical results, the macro fibers can arrest the propagation of macro cracks, resulting in a higher toughness and better ductility of cementitious composites. In recent year, the micro-fibers are also introduced to reinforce the cementitious material [10-13], it is found that the microfibers provide effective reinforcement at the micro cracking level, inhibit the initiation and coalescence of micro cracks into unstable macro cracks, and increase strength. However, the high production cost of micro fiber, such as nanotubes, limited their applications in largescale construction projects.

As the cracking and fracture of cementitious materials is a multi-scale and multi-stage process, hybrid fibers with mutil-scale was introduced to the cementitious material aiming at restraining cracking at different scales during the cracking process [14-16]. In this paper, a new kind of multi-scale engineered cementitious composite (MSECC), which contains polyvinyl alcohol (PVA) fiber and calcium carbonate (CaCO3) whisker, was designed from the perspective of multi-scale structure and fracture process of cementitious material. $\mathrm{CaCO} 3$ whisker is a kind of micrometerscale fibrous material with high strength, high elastic modulus and high aspect ratio and can play an important role in micro-cracking resistance [17-19], the macro and micro morphology of $\mathrm{CaCO} 3$ whisker are shown in Fig 1. In this study, the $\mathrm{CaCO} 3$ whisker and PVA fiber was incorporated into the cementitious composite to design a new kind of fiber hybridization. It is hoped that the designed fiber hybridization can lead to multiscale cracking resistance, from the microscale to the macroscale level, thus improving both the tensile strength and the toughness. Furthermore, as a kind of cheap micro fiber, the production cost of $\mathrm{CaCO} 3$ whisker is only about $\$ 200$ per ton, thus it may be helpful to decrease the production cost of fiber-reinforced cementitious composites for large construction project applications.

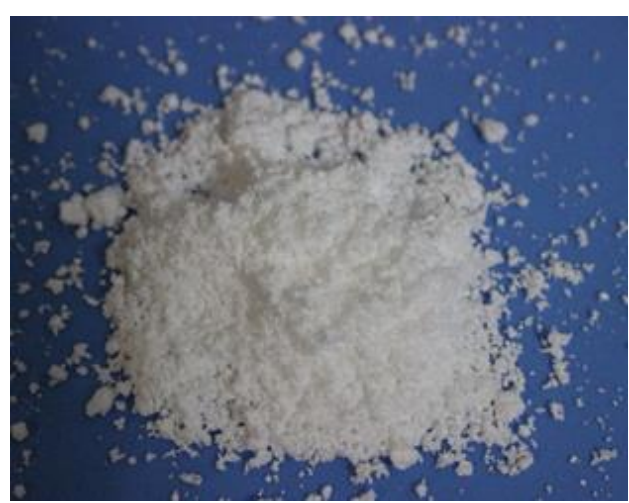

(a)

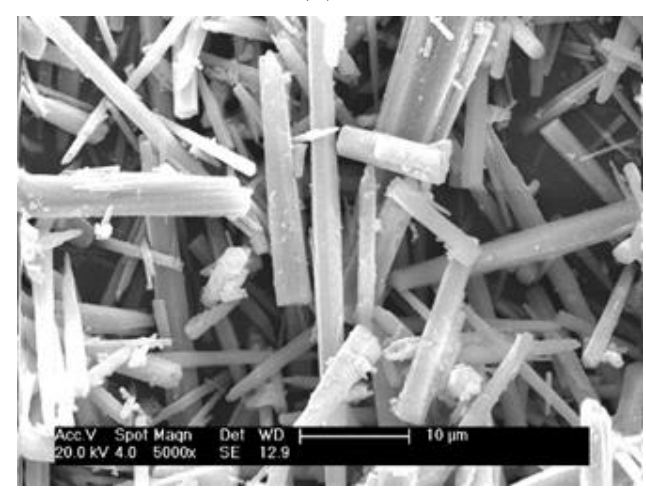

(b)

Figure 1: the morphology of $\mathrm{CaCO} 3$ (a) macro-morphology; (b) micro morphology

\section{EXPERIMENTAL PROGRAM}

The materials including cement (P.O 42.5R), quart sand, fly ash, PVA fiber, and $\mathrm{CaCO} 3$ whisker were used in this study. The physical properties and chemical constituents of the raw materials are shown in Tables 1 and 2, 
respectively.

Table 1. Physical properties of raw materials

\begin{tabular}{|c|c|c|c|}
\hline Materials & $\operatorname{Density}\left(\mathrm{g} / \mathrm{cm}^{3}\right)$ & Mechanical property & Size \\
\hline cement & 3.2 & --- & $45 \mu \mathrm{m}$ sieve residue $14.28 \%$ \\
\hline quart sand & 2.2 & Moh's hardness 7 & $\begin{array}{c}\text { fineness modulus } 2.03 \text {, fine } \\
\text { sand }\end{array}$ \\
\hline fly ash & 2.6 & --- & $45 \mu \mathrm{m}$ sieve residue $9.27 \%$ \\
\hline PVA fiber & 1.3 & $\begin{array}{l}\text { tensile strength } 1620 \\
\text { MPa }\end{array}$ & length $12 \mathrm{~mm}$, diameter $39 \mu \mathrm{m}$ \\
\hline $\begin{array}{l}\mathrm{CaCO} 3 \\
\text { whisker }\end{array}$ & 2.8 & $\begin{array}{l}\text { elastic modulus } 43 \\
\text { GPa } \\
\text { tensile strength 3-6 } \\
\text { GPa } \\
\text { elastic modulus 410- } \\
\text { 710GPa }\end{array}$ & $\begin{array}{l}\text { length } 20-30 \mu \mathrm{m} \text {, diameter } \\
0.5-2 \mu \mathrm{m}\end{array}$ \\
\hline
\end{tabular}

Table 2. Chemical constituents of raw materials (wt \%)

\begin{tabular}{llllllllllll}
\hline \hline Composition & $\mathrm{Ca} 0$ & $\mathrm{SiO} 2$ & $\mathrm{Al2O} 3$ & $\mathrm{Fe} 2 \mathrm{O} 3$ & $\mathrm{C} 02$ & $\mathrm{MgO}$ & $\mathrm{K} 20$ & $\mathrm{SO} 3$ & $\mathrm{Na} 20$ & $\mathrm{P} 2 \mathrm{O} 5$ & $\mathrm{MnO}$ \\
\hline \hline Cement & 61.13 & 21.45 & 5.42 & 2.89 & 2.37 & 2.08 & 0.81 & 2.50 & 0.77 & 0.07 & 0.06 \\
Fly ash & 3.71 & 50.86 & 28.16 & 6.24 & - & 1.28 & 0.67 & 0.85 & 1.27 & - & - \\
whisker & 54.93 & 0.29 & 0.11 & 0.07 & 42.07 & 2.14 & - & 0.31 & - & - & - \\
& & & & & & & - & & & & \\
\hline \hline
\end{tabular}

In this research, the water-binder ratio and the sand-binder ratio were set as
0.28 and 0.2 , respectively. The mix proportion of fibers is shown in Table 3. 
Table 3. Dosage of different fiber combinations

\begin{tabular}{ccccc}
\hline \hline \multirow{2}{*}{ Groups } & \multicolumn{2}{c}{$\begin{array}{c}\text { Volume fraction } \\
(\%)\end{array}$} & \multicolumn{2}{c}{ Fiber dosage $(\mathrm{kg} / \mathrm{m} 3)$} \\
& PVA & CW & PVA & CW \\
\hline \hline M0 & 2 & 0 & 26 & 0 \\
M1 & 1.75 & 0 & 22.75 & 0 \\
M2 & 1.75 & 1 & 22.75 & 28 \\
M3 & 1.75 & 2 & 22.75 & 56 \\
M4 & 1.75 & 4 & 22.75 & 112 \\
M5 & 1.5 & 0 & 19.5 & 0 \\
M6 & 1.5 & 2 & 19.5 & 56 \\
M7 & 1.5 & 4 & 19.5 & 112 \\
M8 & 1.5 & 6 & 19.5 & 168 \\
M9 & 1.25 & 0 & 16.25 & 0 \\
M10 & 1.25 & 2 & 16.25 & 56 \\
M11 & 1.25 & 4 & 16.25 & 112 \\
M12 & 1.25 & 6 & 16.25 & 168 \\
\hline \hline
\end{tabular}

Note: $\mathrm{CW}=\mathrm{CaCO} 3$ whisker; $\mathrm{PVA}=$ polyvinyl alcohol fiber;

A typical ECC mixture (M0) reducing ratio 24.1\%) was varied from without any $\mathrm{CaCO} 3$ whisker was used as a control [20]. In order to ensure the mixtures maintained similar flow and could be cast easily, the amount of water reducer (polycarboxylic acid type, water0.5 to $1.5 \mathrm{wt} \%$ of binder content according to the content of $\mathrm{CaCO} 3$ whisker. The mixing procedures for fresh cementitious mixtures are shown in Fig. 2 .

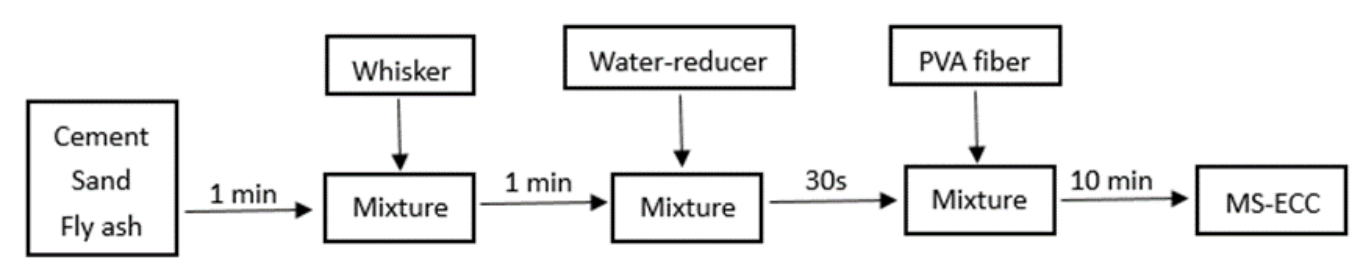

Figure 2. Mixing procedure for fresh cementitious mixtures 


\section{TEST SPECIMEN PREPARATION}

\section{AND TESTING}

After mixing procedure, the fresh mixture was placed into the special molds and vibrated on a vibration machine for 20 s. All specimens were stored in the molds for $24 \mathrm{~h}$; thereafter they were demolded and taken to the constant temperature and humidity curing box for 28 days [21].

The $70 \times 70 \times 70 \mathrm{~mm}$ cubes were used for the compressive test, a pressure machine at a cross-head speed of $2.4 \mathrm{kN} / \mathrm{s}$ was applied to determine the compression strength of the samples [21]. According to JSCE-2008m, samples with dimensions of $40 \times 40 \times 160 \mathrm{~mm}$ were used for the four-point flexural test. The samples for uniaxial tensile test, which is also called dog-bone specimens, are shown in Fig 3 [22]. The test machine and test methods are shown in Fig.4, the microstructures of the composites were examined using a scanning electron microscope (SEM; QUANTA 450, Hillsboro, OR).

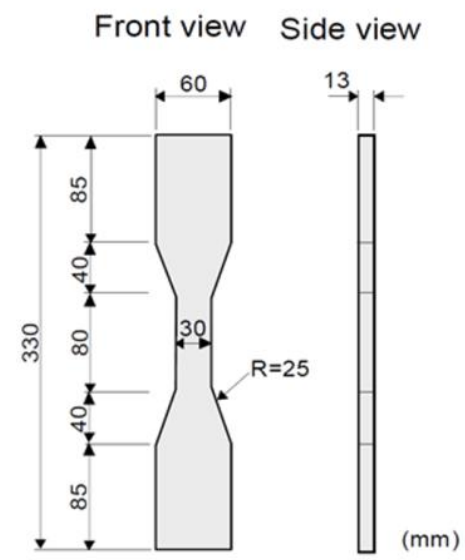

Figure 3 Specimens for uniaxial tensile test

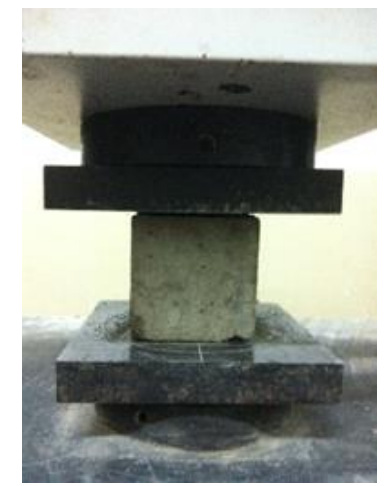

(a)

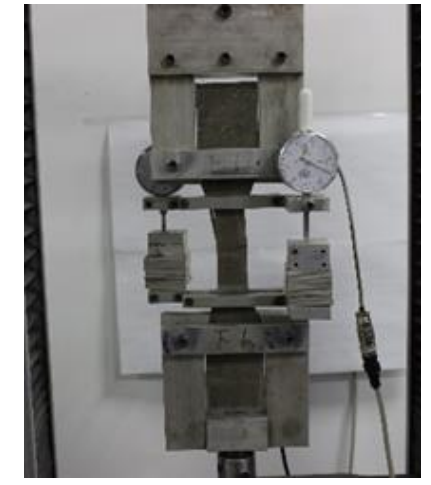

(b)

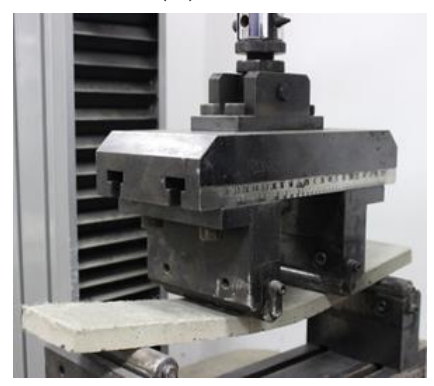

(c)

Figure 4. Test method for (a) compression test; (b) tensile test; (c) flexural test

\section{RESULTS AND DISCUSSION}

\subsection{Compression strength}

The average compression strength values for all mixtures are shown in Fig. 5. It can be seen that the compression strength of typical ECC mixture (M0) is only about $27.6 \mathrm{Mpa}$ owing to the lack of aggregate and high volume of fly ash. The mixture groups M1, M5 and M9 have higher compression strength because these mixture containing less 
PVA fiber. This is because the numerous interface between PVA fiber and matrix may degrade the compression strength, therefore the composite may have lower strength with the increase of volume fraction of PVA fiber. For composites with a PVA volume fraction of $1.75 \%$ (M1 to M4), the composites containing $\mathrm{CaCO} 3$ whisker had a higher compression strength than that of the control group which containing monoPVA fiber. Similar trends were found for the composite with a PVA volume fraction of $1.5 \%$ and $1.25 \%$. This is likely a result of the filler effect $\mathrm{CaCO} 3$ whisker, which could increase the compactness and compressive strength. For the PVA volume fraction of $1.25 \%$, the use of a $2 \%$ volume of $\mathrm{CaCO} 3$ whisker (M10) caused a $5.54 \%$ increase in compressive strength compare to M9, however, the descend trend in in composite strength was observed along with the further increase of $\mathrm{CaCO} 3$ whisker. Similar trends were also found for the composite with a PVA volume fraction of $1.75 \%$ and $1.5 \%$. Poor dispersion and agglomeration of $\mathrm{CaCO} 3$ whisker in high concentrations may account for this issue [17].

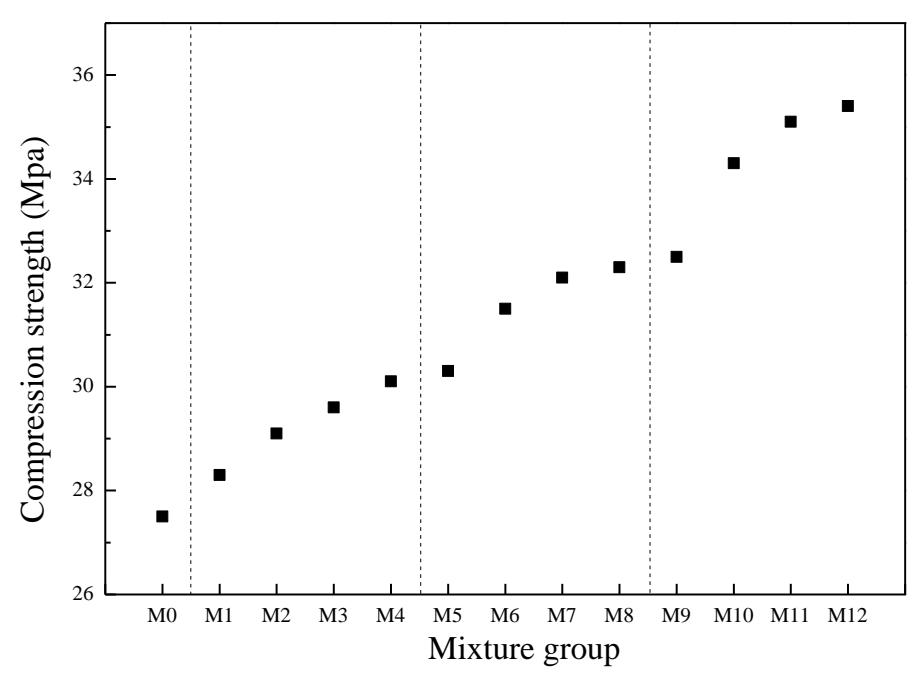

Figure5: Average compression strengths of the matrix groups

\subsection{Flexural behaviors}

The flexural responses of all mixtures are showing in Fig 6.

Fig6 (a) is the typical loaddeflection curves for ECC, the strain hardening behavior accompanied with the formation of multiple cracks can be observed in the load-deflection curves.

Fig6 (b) is the load-deflection curves for composite with the PVA volume fraction of $1.75 \%$. For the composite with mono-PVA fiber (M1), both the ultimate load and ultimate deflection are reduced compared with M0, as well as the loss of strain hardening behavior. This is due to the reduction of PVA fiber content, thus the fiber bridgeeffect was also reduced. The addition of $1 \%$ volume fraction of whisker improved both the ultimate load and ultimate deflection of the composite. The flexural responses of M2 is almost similar to M0 even though M2 has less volume fraction of PVA fiber. It can also be seen that the ultimate deflection improved with the further increase in whisker content whereas the ultimate load decreased with 
the further increase of whisker contend.

The load-deflection curves for composite with the PVA volume fraction of $1.5 \%$ are shown in Fig6 (c). The ultimate deflection and ultimate load of M5 were further reduced compared to M0 due to the further reduction of PVA fiber. The addition of $2 \%$ volume fraction of $\mathrm{CaCO} 3$ whisker into the M5 matrix brought great improvement to the flexural performance of the composite. This is likely due to the multiscale design of the fibers. The $\mathrm{CaCO} 3$ whiskers could inhibit the initiation and propagation of micro cracks. Thus multiple micro cracks would be formed in the cement matrix, and the macro cracks may not be easily formed. Therefore, less content of PVA fiber could be possible to inhibit the initiation and propagation of macro cracks. Further addition of $\mathrm{CaCO} 3$ whisker (M7, M8) could increase the ultimate deflection of the composite, however, poor dispersion and agglomeration of $\mathrm{CaCO} 3$ whisker in high concentrations may decrease the ultimate load of the composite.

Fig6 (d) shows the load-deflection curves for mixtures with the PVA fiber volume fraction of $1.25 \%$. Both the ultimate deflection and load of the mixtures were further reduced due to the less content of PVA fiber. In this case, the addition of $2 \%$ volume fraction of $\mathrm{CaCO} 3$ whisker caused $34 \%$ ultimate load increase and $108 \%$ ultimate deflection increase. Compared to M10, the further addition of $\mathrm{CaCO} 3$ whisker (M11) is also brought further improvement both in ultimate load and ultimate deflection, which is quite different from other mixtures. However, the $6 \%$ volume fraction of $\mathrm{CaCO} 3$ whisker leads to a decrease to their flexural performance, which indicates $4 \%$ volume fraction of $\mathrm{CaCO} 3$ may be the best content in this case.

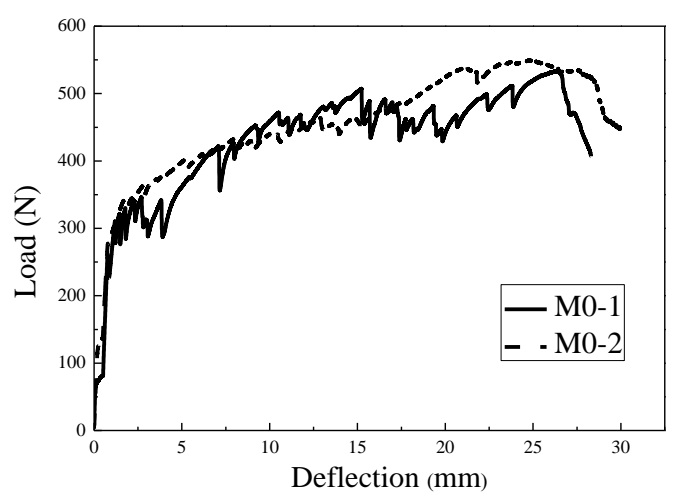

(a)

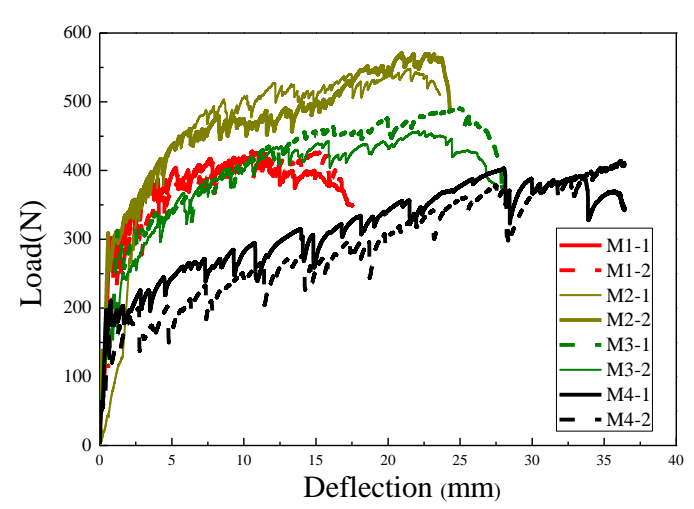

(b)

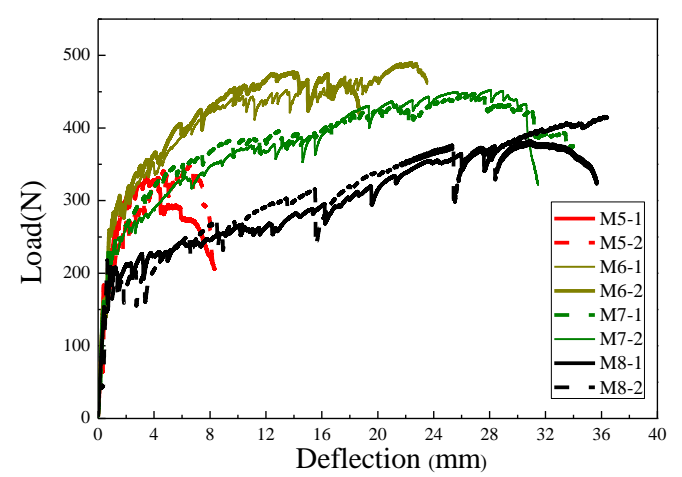

(c) 


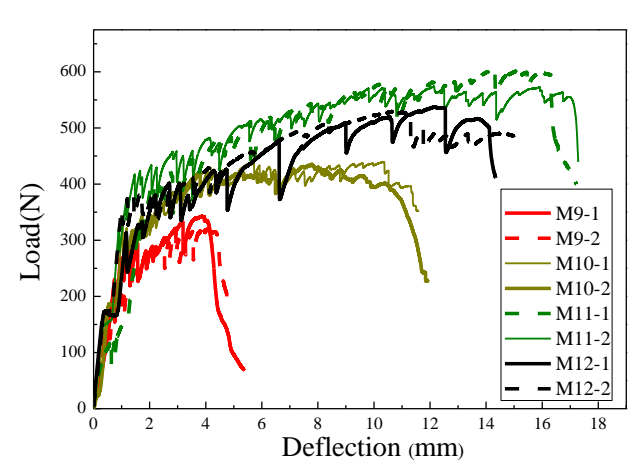

(d)

Figure 6: PVA volume fraction of (a) $2 \%$ (b) $1.75 \%$ (c) $1.5 \%$ (d) $1.25 \%$

\subsection{Tensile behaviors}

The tensile behaviors of composites are showing in Fig 7.

Fig7 (a) is the typical stress-strain curves for ECC material under uniaxial tensile load, according to the stress-strain curves, the ultimate strain is $3.4 \%$, which can be classified as ultra-high ductile cementitious material, the strain hardening behavior and multiple cracks mode can also be observed in the stressstrain curves.

Fig7 (b) is the stress-strain curves for mixture with $1.75 \%$ PVA fiber volume fraction. For the composite with mono-PVA fiber (M1), both the ultimate stress and ultimate strain are reduced compared with M0, as well as the loss of strain hardening behavior. The addition of $1 \%$ volume fraction of whisker (M2) recovered the strain-harding behavior of the mixture, as well as improved both the ultimate stress and strain. The stressstrain curves for M2 is almost similar to M0 even though M1 has less volume fraction of PVA fiber, indicating that the PVA fiber can be appropriately replaced by $\mathrm{CaCO} 3$ whisker, which is beneficial in decreasing the production cost of fiberreinforced cementitious composites for large-scale construction projects. Further addition of $\mathrm{CaCO} 3$ whisker will reduce both the ultimate stress and strain, which may due to the poor dispersion and agglomeration of $\mathrm{CaCO} 3$ whisker.

The uniaxial tensile behavior for composite with the PVA volume fraction of $1.5 \%$ are shown in Fig7 (c). The ultimate deflection and ultimate load of M5 were further reduced compared to M0 due to the lack of PVA fiber. According to the test results, the addition of $4 \%$ volume fraction of $\mathrm{CaCO} 3$ whisker into the M5 mixture brought the best uniaxial tensile performance of the composite.

Fig7 (d) shows the loaddeflection curves for the composites with PVA volume fraction of $1.25 \%$. The ultimate strain of the composite M9 was $1 \%$, which cannot be classified as ultrahigh ductility cementitious material. The addition of $2 \%$ volume fraction of $\mathrm{CaCO} 3$ whisker caused $86 \%$ ultimate load increase and $112 \%$ ultimate deflection increase. According to the test results, the addition of $4 \%$ volume fraction of $\mathrm{CaCO} 3$ whisker into the M9 matrix may be the best ratio in this case.

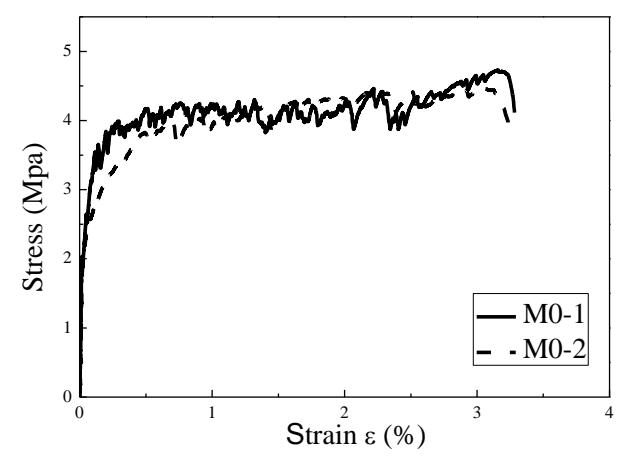

(a) 


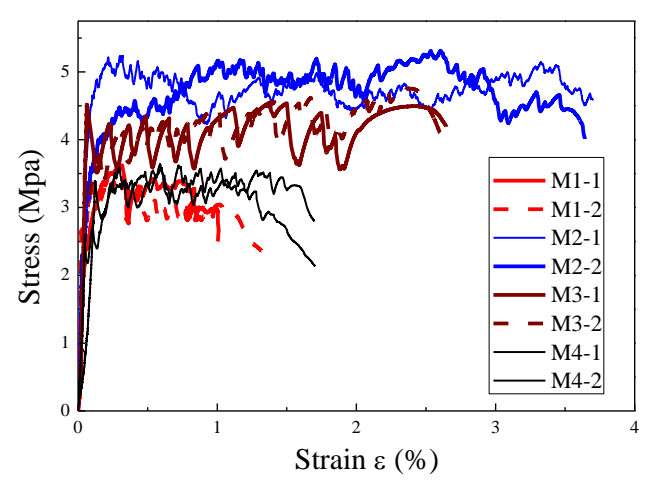

(b)

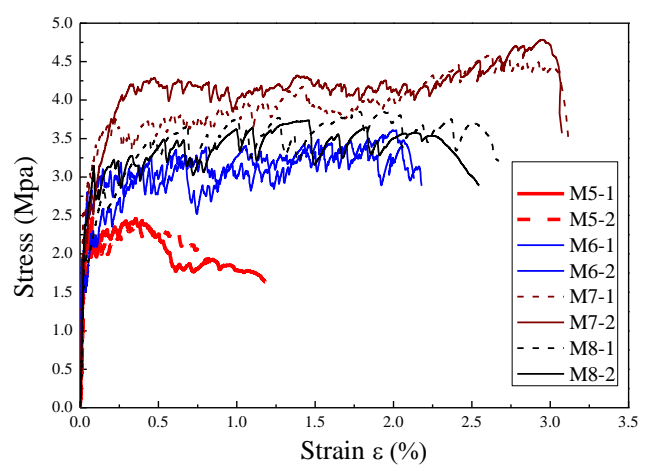

(c)

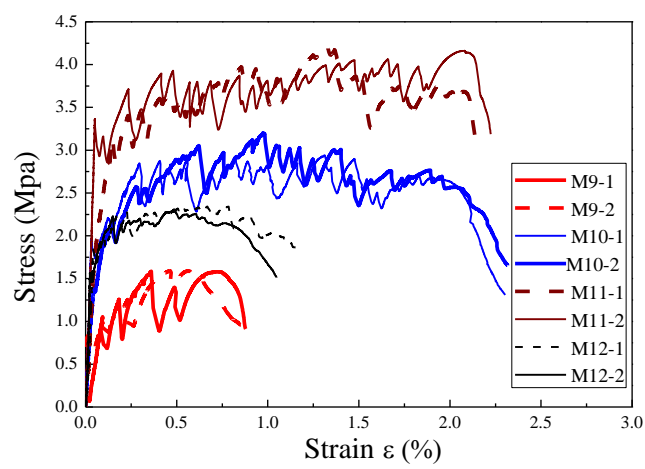

(d)

Figure 7: PVA volume fraction of (a)
$2 \%$
(b) $1.75 \%$
(c) $1.5 \%$
(d) $1.25 \%$

\section{CONCLUSIONS}

As the cracking and fracture of cementitious materials is a multi-scale and multi-stage process, a new kind of multi-scale engineered cementitious composite (MS-ECC) containing polyvinyl alcohol (PVA) fiber and calcium carbonate $(\mathrm{CaCO} 3)$ whisker was established in this study, based on the results, the following conclusions can be drawn:

1.The designed MS-ECC improves the compressive strength of mono PVA ECC composites slightly, and it brings significant improvement to both flexural and tensile behavior of the mixture with proper content of $\mathrm{CaCO} 3$ whisker. Overdose of $\mathrm{CaCO} 3$ whisker could increase the ductility of the composite due to the incorporation of artificial flaws, however, poor dispersion and agglomeration of $\mathrm{CaCO} 3$ whisker in high concentrations may decrease the load carrying capacity of the mixture.

2. The $\mathrm{CaCO} 3$ whisker and PVA fiber effectively interact with different scales in the designed MS-ECC. The $\mathrm{CaCO} 3$ whiskers delay the formation and propagation of micro cracks at the micro level, whereas the PVA fibers interact with mesocracks and macro cracks effectively.

3.The strain-hardening behavior and multiple cracking patterns of the designed MS-ECC can be achieved under uniaxial tension even though the volume fraction of PVA fiber was only $1.25 \%$. It seems possible that the PVA fibers can be partly replaced with cheap $\mathrm{CaCO} 3$ whiskers, which is beneficial in decreasing the production cost of engineered cementitious composites for large-scale construction project applications.

\section{ACKNOWLEDGMENT}

Financial support of this work by National Natural Science Foundation of China under 51278118 and Priority Academic Program Development of Jiangsu High Education Institutions under 1105007002 is gratefully 
acknowledged.

\section{REFERENCES}

[1] $\mathrm{Li} \mathrm{V}$ C, Wang $\mathrm{S}$, Wu C. 2001. Tensile strain-hardening behavior of polyvinyl alcohol engineered cementitious composite (PVA-ECC). ACI materials Journal, 98(6): 483-492. [2] Song P S, Hwang S. 2004. Mechanical properties of high-strength steel fiber-reinforced concrete. Construction and Building Materials, 18(9): 669-673.

[3] Bayasi Z, Zeng J. 1993.Properties of polypropylene fiber reinforced concrete. ACI Materials Journal, 90: 605-605.

[4] Hahne H, Karl S, Worner J D. 1987. Properties of polyacrylonitrile fiber reinforced concrete. ACI Special Publication, 105: 211-224.

[5] Yue Y, Li G, Xu X, et al. 2000. Properties and microstructures of plant-fiber-reinforced cement-based composites. Cement and Concrete Research, 30(12): 1983-1986.

[6] Yao W, Li J, Wu K. 2003. Mechanical properties of hybrid fiberreinforced concrete at low fiber volume fraction. Cement and concrete research, 33(1): 27-30.

[7] Hossain K M A, Lachemi M, Sammour M, et al. 2013. Strength and fracture energy characteristics of selfconsolidating concrete incorporating polyvinyl alcohol, steel and hybrid fibres. Construction and Building Materials, 45: 20-29.

[8] Qian C, Stroeven P. 2000. Fracture properties of concrete reinforced with steel-polypropylene hybrid fibres. Cement and Concrete Composites, 22(5): 343-351.
[9] Lawler J S, Wilhelm T, Zampini D, et al. 2003. Fracture processes of hybrid fiber-reinforced mortar. Materials and Structures, 36(3): 197208.

[10] Banthia N, Sheng J. 1996. Fracture toughness of micro-fiber reinforced cement composites. Cement and Concrete Composites, 18(4): 251269.

[11] Hamoush S, Abu-Lebdeh T, Cummins T. 2010. Deflection behavior of concrete beams reinforced with PVA micro-fibers. Construction and Building Materials, 24(11): 2285-2293. [12] Yakovlev G, Kerienè J, Gailius A, et al. 2006. Cement based foam concrete reinforced by carbon nanotubes. Materials Science [Medžiagotyra], 12(2): 147-151.

[13] Metaxa Z S, Konsta-Gdoutos M S, Shah S P. 2009. Carbon nanotubes reinforced concrete. ACI Special Publication, 267: 11-20.

[14] Parant E, Rossi P, Boulay C. 2007. Fatigue behavior of a multi-scale cement composite. Cement and Concrete Research, 37(2): 264-269.

[15] Parant E, Pierre R, Le Maou F. 2007. Durability of a multiscale fibre reinforced cement composite in aggressive environment under service load. Cement and concrete research, 37(7): 1106-1114.

[16] Cao M, Zhang C, Li Y, et al. 2014. Using Calcium Carbonate Whisker in Hybrid Fiber-Reinforced Cementitious Composites. Journal of Materials in Civil Engineering, 27(4): 04014139.

[17] Cao M, Zhang C, Lv H, et al. 2014. Characterization of mechanical behavior and mechanism of calcium carbonate whisker-reinforced cement 
mortar. Construction and Building Materials, 66: 89-97.

[18] Cao M, Zhang C, Wei J. 2013. Microscopic reinforcement for cement based composite materials. Construction and Building Materials, 40: 14-25.

[19] Li M, Yang Y, Liu M, et al. 2015. Hybrid effect of calcium carbonate whisker and carbon fiber on the mechanical properties and microstructure of oil well cement. Construction and Building Materials, 93: 995-1002.

[20] Wang S, Li V C. 2007. Engineered cementitious composites with high-volume fly ash. Materials Journal, 104(3): 233-241.

[21] ISO. (2009). "Cement - Test methods - Determination of strength." ISO 679:2009, Geneva.

[22] JSCE (2008). "JSCE-2008m JSCE. Recommendations for Design and Construction of High Performance Fiber Reinforced Cement Composites with Multiple Fine Cracks ( HPFRCC)", 2008.

[23] Maekawa K, Ishida T, Kishi T. 2003. Multi-scale modeling of concrete performance. Journal of Advanced Concrete Technology, 1(2): 91-126. 